EXTENDED REPORT

\title{
Elevated aqueous humour tissue inhibitor of matrix metalloproteinase- 1 and connective tissue growth factor in pseudoexfoliation syndrome
}

\author{
S L Ho, G F Dogar, J Wang, J Crean, Q D Wu, N Oliver, S Weitz, A Murray, P E Cleary, C O’Brien
}

Br J Ophthalmol 2005;89:169-173. doi: 10.1136/bjo.2004.044685

See end of article for authors' affiliations

Correspondence to:

Su Ling Ho, Department of Ophthalmology, Mater

Misericordiae Hospital,

Eccles Street, Dublin 7, Ireland; sulingho@

eircom.net

Accepted for publication 8 July 2004
Background/aims: Pseudoexfoliation syndrome (PXF) was recently found to be associated with increased expression of transforming growth factor $\beta_{1}\left(\mathrm{TGF} \beta_{1}\right)$ in the aqueous humour. As concern has been raised regarding anti-TGF $\beta$ therapy, which can potentially disrupt the maintenance of anterior chamber associated immune deviation, the authors explored the levels of tissue inhibitor of matrix metalloproteinase- 1 (TIMP-1), matrix metalloproteinase-9 (MMP-9), and connective tissue growth factor (CTGF) in aqueous humour to determine if these may represent alternative therapeutic targets.

Methods: Aqueous humour samples were collected from patients who underwent routine cataract surgery. All patients were categorised into three main groups - PXF, uveitis, and control. The PXF group was further subcategorised into three grades based on the density of the exfoliative material observed on biomicroscopy, as well as the presence or absence of glaucoma. TIMP-1, MMP-9, and CTGF levels were measured using specific enzyme immunoassays (ELISA).

Results: Eyes with PXF had significantly higher aqueous humour TIMP-1 concentration ( $n=56$, mean (SE), $9.76(1.10) \mathrm{ng} / \mathrm{ml}$ ) compared with controls $(\mathrm{n}=112,5.73(0.43) \mathrm{ng} / \mathrm{ml}, \mathrm{p}<0.01)$. Similarly, the CTGF level in PXF eyes $(n=36,4.38(0.65) \mathrm{ng} / \mathrm{ml})$ was higher than controls $(\mathrm{n}=29,2.35(0.46) \mathrm{ng} / \mathrm{ml}$, $\mathrm{p}<0.05)$. Further, the CTGF concentration in the PXF glaucoma group is significantly higher compared with PXF eyes without glaucoma (6.03 (1.09) ng/ml v $2.73(0.45) \mathrm{ng} / \mathrm{ml}, \mathrm{p}<0.01)$. The MMP-9 levels were low and below detection limit in all PXF and control samples with no statistical difference between groups.

Conclusion: A raised TIMP-1 level and a low MMP-9 level in aqueous humour of PXF eyes may imply a downregulation in proteolytic activity. The increased CTGF concentration supports the proposed fibrotic pathology of PXF. Regulation of MMP/TIMP expression and anti-CTGF therapy may offer potential therapeutic avenues for controlling PXF associated ocular morbidity.
$\mathrm{T}$ here has been an increasing awareness of the role of growth factors in aqueous humour homeostasis leading to the development of raised intraocular pressure and glaucoma. ${ }^{12}$ As the aqueous humour bathes the anterior segment, its compounds affect the metabolic functioning of the cells lining the conventional outflow routes-that is, the trabecular meshwork (TM). In humans, the TM is made up of collagen beams covered by endothelial-like cells. The spaces between the beams are filled with extracellular matrix (ECM). The ECM in the subendothelial region of Schlemm's canal plays an important part in the pathogenesis of glaucoma. ${ }^{3}$ Elevated intraocular pressure may be attributed to abnormal deposition of ECM resulting in a reduced filtration capacity. ${ }^{34}$

Characterised by progressive accumulation of a fibrillar extracellular material most notable on the pupillary border and anterior lens capsule, pseudoexfoliation syndrome (PXF) encompasses more than half of the cases of open angle glaucoma in Norway, Ireland, Greece, and Saudi Arabia. ${ }^{56}$ The exact biochemical nature of the exfoliative material, the mechanism of its production, and pathophysiology leading to elevated intraocular pressure in PXF remain to be unravelled.

Recent studies have found PXF to be associated with increased levels of transforming growth factor $\beta_{1}\left(\mathrm{TGF} \beta_{1}\right),{ }^{78}$ basic fibroblast growth factor (bFGF), ${ }^{9}$ and hepatocyte growth factor (HGF), ${ }^{10}$ and 8 -isoprostaglandin F2a (8-IPGF) ${ }^{11}$ in the aqueous humour. It has been speculated that these findings are indicative of oxidative stress as well as an abnormality in fibrogenesis, matrix degradation, and cellular response to injury in the anterior segment of PXF eyes.

$\mathrm{TGF} \beta_{1}$, a fibrogenic cytokine, has a pivotal role in the ocular wound healing processes. It is also essential in the maintenance of the anterior chamber associated immune derivation (ACAID). ${ }^{2}$ It promotes deposition of ECM by downregulating the production of proteases and stimulating the synthesis of protease inhibitors. ${ }^{12-14}$ Huang et al demonstrated the presence of matrix metalloproteinases (MMP) and tissue inhibitors of matrix metalloproteinases (TIMP) in normal aqueous humour. They suggested that an imbalance in the MMP/TIMP ratio may contribute to anterior eye segment ECM alteration associated with ocular neovascularisation and glaucoma. ${ }^{15}$ Connective tissue growth factor (CTGF), also plays a part in the ECM deposition remodelling and wound healing. Studies have shown that CTGF is an essential downstream mediator of many of the effects of TGF $\beta_{1}$, particularly those associated with fibrosis, ${ }^{16}{ }^{17}$ and CTGF has been detected in human aqueous humour. ${ }^{18}$

As concern has been raised regarding anti-TGF $\beta_{1}$ therapy which can potentially disrupt the maintenance of ACAID, ${ }^{1}$ we

Abbreviations: ACAID, anterior chamber associated immune derivation; bFGF, basic fibroblast growth factor; CTGF, connective tissue growth factor; ECM, extracellular matrix; HGF, hepatocyte growth factor; 8-IPGF, 8-isoprostaglandin F2a; PXF, pseudoexfoliation syndrome; MMP-9, matrix metalloproteinase-9; TGF $\beta$, transforming growth factor $\beta$; TIMP-1, tissue inhibitor of matrix metalloproteinase-1; TM, trabecular meshwork 
explored the levels of TIMP-1, MMP-9, and CTGF in aqueous humour as these may represent alternative therapeutic targets for controlling PXF associated ocular morbidity.

\section{MATERIALS AND METHODS}

Aqueous humour was obtained from patients who underwent routine cataract surgery. All patients had slit lamp examination on the day before or on the morning before surgery by the same investigator (SLH) and they were categorised into three main groups:

- Pseudoexfoliation syndrome (PXF)

- Past history of intraocular surgery or ocular inflammatory diseases

- Control (no signs of intraocular pathology apart from cataract).

The pseudoexfoliation group was further subcategorised into three grades based on the biomicroscopy findings.

- PXF grade I (Al): PXF material only visible after pupillary dilatation

- PXF grade II (A2): PXF material visible scattered discontinuously along pupillary margin and anterior lens capsule before pupillary dilatation without iridodonesis or phacodonesis

- PXF grade III (A3): Dense PXF material visible continuously along the circumference of pupillary margin before dilatation with or without iridodonesis or phacodonesis.

In addition, the PXF group was divided into two subcategories-that is, PXF without glaucoma and PXF with glaucoma based on case notes history.

Patients with glaucoma were maintained on their preoperative antiglaucoma medication (ranging from timolol (MSD), betaxolol (Alcon), levobunolol (Allergen), dorzolamide/timolol(MSD), or latanoprost (Pfizer) monotherapy in combinations of the above with brimonidine (Allergen), brinzolamide (Alcon), dorzolamide (MSD), or apraclonidine (Alcon)). All patients who underwent cataract surgery were given topical ocular premedication of $2.5 \%$ phenylephrine hydrochloride, $1 \%$ cyclopentolate hydrochloride, and $0.5 \%$ chloramphenicol preservative free drops before surgery. Data on medical history, medications, and demographic information were obtained from the case notes.

\section{Aqueous humour sampling}

Samples of aqueous humour were obtained in the first intraocular manoeuvre (paracentesis site for phacoemulsification cases or first full thickness entry wound from a stepped corneolimbal incision for extracapsular extraction). Aqueous humour was aspirated into a $1 \mathrm{ml}$ insulin syringe with a Rycroft cannula (Maersk Medical Ltd, Redditch, UK). Meticulous care was taken to avoid touching the iris, lens, and corneal endothelium and to prevent contamination of the aqueous sample from irrigation fluid and blood from the conjunctiva. A 100-150 $\mu \mathrm{l}$ sample of aqueous humour was collected from each patient. The aqueous humour sample was immediately stored at $4^{\circ} \mathrm{C}$ in the eye theatre fridge and was transferred to the surgical laboratory within the next 2 hours to be stored at $-80^{\circ} \mathrm{C}$ until used.

Informed consent to the aqueous humour contribution was obtained from patients, and the research protocol was approved by the clinical research ethics committee of the Cork Teaching Hospitals and Mater Misericordiae Hospital.

A total of 202 aqueous humour samples were collected; 121 samples were from female subjects and 81 were from male. Out of these, we had 69 samples which came from patients with PXF (mean (SE) age, 79.9 (0.65) years; range,
69-91 years), 17 from patient with recent ocular surgery or uveitis (65.8 (3.85) years; range 27-86 years), and 116 samples from control subjects (75.5 (0.78) years; range 4892 years).

\section{Enzyme immunoassays}

\section{TIMP- 1 and MMP-9}

The concentration of the aqueous humour TIMP-1 and total MMP-9 (active and pro-MMP-9) were quantified using commercially available sandwich enzyme immunoassay kits (Quantikine, R\&D systems, Abingdon, UK) with a minimum detectable concentration of $0.08 \mathrm{ng} / \mathrm{ml}$ and $0.156 \mathrm{ng} / \mathrm{ml}$ respectively. A 25-fold dilution was applied for the sample preparation during TIMP-1 assay and a 10-fold dilution for MMP-9 assay. Each ELISA kit has a specificity of detecting native human as well as recombinant TIMP-1 or MMP-9. A standard calibration curve was generated using the standard TIMP-1 or MMP-9 provided by the manufacturer: with seven standard solution within a range of $0.156-10 \mathrm{ng} / \mathrm{ml}$ for TIMP- 1 and with six standard solution ranging from 0.312 to $10 \mathrm{ng} / \mathrm{ml}$ for MMP-9. Each TIMP-1 and MMP-9 assay was performed in duplicate according to the manufacturer's advice.

\section{CTGF}

CTGF sandwich ELISAs were performed by FibroGen Inc (South San Francisco, CA, USA) to determine the aqueous humour content of whole CTGF and N-terminal half fragments of CTGF. These sandwich ELISAs use pairs of CTGF specific monoclonal antibodies that allow capture and detection of: (1) whole CTGF; and (2) whole CTGF+Nterminal CTGF fragments. ${ }^{19}$ Content of $\mathrm{N}$-terminal fragment of CTGF was determined by subtracting the content of whole CTGF from the content of whole CTGF+N-terminal CTGF fragments (that is, (2) minus (1)). CTGF can undergo proteolysis and its bioactivity has been reported from resulting fragments. ${ }^{20-22}$ The $\mathrm{N}$-terminal fragments appear more stable than whole CTGF. ${ }^{19}$ Therefore, determining levels of both whole CTGF as well as N-terminal CTGF fragments provides an accurate measurement of total CTGF production and processing.

A range finding experiment was first conducted to determine the most suitable sample dilution. Spike recovery experiments using recombinant human CTGF (rhCTGF) have demonstrated that the CTGF sandwich ELISAs provide quantitative detection in samples of various biological fluids. ${ }^{19}$ Since the CTGF ELISA antibodies do not cross react with CCN gene family members Cyr61 and Nov, these related proteins are not detected in these assays. Controls are included to ensure that plate to plate variation is $<20 \%$ and triplicate assays were performed for each sample. For the reported studies, standard curves were generated using rhCTGF and assay minimum detectable concentration was determined to be $2 \mathrm{ng} / \mathrm{ml}$.

We also statistically analysed our data using values of: (1) whole CTGF only, (2) N-terminal fragment only, and (3) ratio of $\mathrm{N}$-fragment/whole CTGF. The overall results using the above three categories are similar to the statistical analysis using the whole $\mathrm{CTGF}+\mathrm{N}$ fragment values. This implies that increased expression (not fragmentation) of CTGF plays an important part in our findings. The CTGF levels reported here are the values of the whole CTGF+Nterminal CTGF fragments.

\section{Statistics}

Results of the immunoassays were expressed as mean (SEM). Kolmogorov-Smirnov test was used to determine normal distribution of the data. The group means were compared and analysed using Fisher's protected least significance 
Table 1 Aqueous humour assay values in experimental groups (I)

\begin{tabular}{|c|c|c|}
\hline \multirow[b]{2}{*}{ Group } & \multicolumn{2}{|l|}{ Mean (SEM) (ng/ml) } \\
\hline & TIMP-1 & CTGF \\
\hline $\begin{array}{l}\text { A:(A1+A2+A3) All PXF } \\
\text { A1: (PXF grade I) } \\
\text { A2: (PXF grade II) } \\
\text { A3: (PXF grade III) } \\
\text { B: Uveitis } \\
\text { C: Controls }\end{array}$ & $\begin{array}{l}9.76(1.10)^{*}(n=56) \\
5.33(0.57)(n=9) \\
10.34(1.47)(n=37) \\
11.61(2.55)(n=10) \\
14.92(3.38)(n=11) \\
5.73(0.43)(n=112)\end{array}$ & $\begin{array}{l}4.38(0.65) \dagger(n=36) \\
3.44(1.03)(n=5) \\
3.89(0.65)(n=24) \\
6.74(2.28)(n=7) \\
7.07(1.98)(n=12) \\
2.35(0.46)(n=29)\end{array}$ \\
\hline
\end{tabular}

difference (Fisher's PLSD) test and Bonferroni/Dunn test after one way analysis of variance (ANOVA) identified statistically significant differences. a p value of less than 0.05 was considered to be statistically significant for Fisher's PLSD test, and likewise less than 0.0167 for Bonferroni/Dunn test (software: StatView; SAS Institute, Cary, NC, USA). The above two post hoc tests were chosen to account for the known increase rate of type I and II error in Fisher PLSD and Bonferroni/Dunn test respectively.

\section{RESULTS}

The PXF group (see table 1) showed a significantly higher TIMP-1 (9.76 (1.10) ng/ml, $\mathrm{n}=56 v$ control $5.73(0.43) \mathrm{ng} /$ $\mathrm{ml}, \mathrm{n}=112)$ and CTGF (4.38 (0.65) ng/ml, $\mathrm{n}=36 v$ control $2.35(0.46) \mathrm{ng} / \mathrm{ml}, \mathrm{n}=29$ ) concentrations compared with the controls, achieving p value of 0.0002 and 0.048 respectively. The higher the PXF grade the higher the TIMP-1 and CTGF levels as well as presence of glaucoma. None of the PXF grade I eyes have glaucoma, whereas over $50 \%$ of the eyes in PXF grade III group were on treatment for glaucoma. Such clinicomorphological observations of the amount of PXF material in the anterior eye segment are potential reliable indicators of disease progression and risk of glaucoma. Histologically, the amount of PXF material in the juxtacanalicular tissue and the outflow filtration area has been proved to correlate with intraocular pressure and optic nerve damage by the Lütjen-Drecoll group. ${ }^{23}$

We also compared the results under the categories of PXF without glaucoma, PXF with glaucoma, and the controls (see table 2). The PXF glaucoma group had a higher TIMP-1 level than PXF without glaucoma. However, this is not statistically significant with a p value of 0.11 . The fact that seven subjects of the PXF glaucoma group were receiving topical prostaglandin analogue (latanoprost $0.005 \%$ ) treatment may have a role in the disease modification. It has been documented in various studies that latanoprost can alter the expression of MMP/TIMP in human explant organ cultures, ${ }^{24}$ Tenon fibroblasts, ${ }^{25}$ ciliary muscle cells, ${ }^{26}$ and rabbit conjunctiva. ${ }^{27}$
However, the effect of latanoprost in our current study is difficult to extrapolate because most patients used more than one type of antiglaucoma medication before surgery at variable duration ranging from weeks to years. On the other hand, the CTGF concentration in the PXF glaucoma group (6.03 (1.09) ng/ml, $\mathrm{n}=18$ ) is significantly higher than PXF without glaucoma $(2.73(0.45) \mathrm{ng} / \mathrm{ml} ; \mathrm{n}=18)$, achieving a $\mathrm{p}$ value of 0.002 (see fig 1 ).

We also postulated that PXF glaucoma is a consequential event from an abnormal wound healing response possibly initiated by the aggregation of PXF material in ocular tissue, leading to a low grade inflammatory response with impaired blood-aqueous barrier. As shown in table l, the uveitis group with known defective blood-aqueous barrier also has very

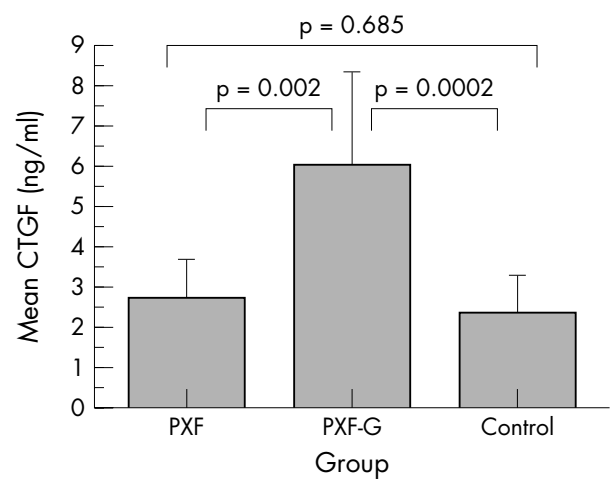

Figure 1 Comparison of aqueous humour CTGF (connective tissue growth factor) levels among PXF (pseudoexfoliation syndrome) without glaucoma (PXF), treated PXF glaucoma (PXF-G), and control groups. Data were represented as mean (SEM) as depicted on the bar chart. The group means were compared and analysed using Fisher's protected least significance difference (Fisher's PLSD) test and Bonferroni/Dunn test after one way analysis of variance (ANOVA) identified statistically significant differences (software: StatView; SAS Institute, Cary, NC, USA). A p value of 0.05 (Fisher's PLSD) or 0.0167 (Bonferroni/Dunn) was considered to be statistically significant.

Table 2 Aqueous humour assay values in experimental groups (II)

\begin{tabular}{lll}
\hline & Mean $($ SEM) $(\mathrm{ng} / \mathrm{ml})$ & \\
\cline { 2 - 3 } Group & TIMP-1 & CTGF \\
\hline PXF without glaucoma & $8.84(1.34)^{*}(n=37)$ & $2.73(0.45)(n=18)$ \\
PXF with glaucoma & $11.55(1.88)^{*}(n=19)$ & $6.03(1.09)^{*}(n=18)$ \\
Control & $5.73(0.43)(n=112)$ & $2.35(0.46)(n=29)$ \\
\hline
\end{tabular}

The group means were compared and analysed using Fisher's PLSD test and Bonferroni/Dunn test after one way analysis of variance (ANOVA) indicated a significant difference (StatView, SAS Institute, Cary, NC, USA). ${ }^{*} \mathrm{p}<0.01$ compare with control (significant for both Fisher's PLSD and Bonferroni/Dunn tests). TIMP-1, tissue inhibitor of metalloproteinase-1; CTGF, connective tissue growth factor; PXF, pseudoexfoliation syndrome. 
raised levels of TIMP- 1 and CTGF. The above findings in the uveitis group, however, should be considered as preliminary observations as they only represent a small number of samples compared with the controls.

Apart from two samples in the uveitis group which were regarded as outliers where the MMP-9 levels were measured at 52.0 and $52.8 \mathrm{ng} / \mathrm{ml}$ respectively, the MMP-9 levels in all the other aqueous humour samples (PXF, $\mathrm{n}=55$; uveitis, $\mathrm{n}=10$; controls, $\mathrm{n}=85$ ) were low and below the detection limits of our commercially obtained ELISA kits.

\section{DISCUSSION}

Degradation of ECM protein is orchestrated by matrix metalloproteinases (MMPs), a family of zinc dependent endopeptidases, whose activity is in turn regulated by their physiological inhibitors known as tissue inhibitors of metalloproteinases (TIMPs). TIMPs are expressed by a wide spectrum of cells and are present in most tissue and body fluids. They also have important regulatory activities independent of MMP inhibition including the promotion of growth, alteration of cell morphology, and modulation of inflammation..$^{28}{ }^{29}$ As aqueous humour is closely linked to the structural and functional integrity of the trabecular meshwork, the presence of altered MMP/TIMP levels in the aqueous humour may well affect the homeostasis of cells lining the conventional outflow routes. The expression of MMPs and their inhibitors by human trabecular meshwork cells also serves an important role in the ongoing trabecular meshwork ECM turnover and subsequent regulation of trabecular outflow resistance. ${ }^{30-33}$ Bradley et al demonstrated in their perfused human anterior segment organ culture study that TIMPs suppressed aqueous outflow rates. ${ }^{31}$ TIMP-1 is the inhibitor for MMP-9 and it can bind to both the latent and active form of the enzyme. ${ }^{34}$

Our current study showed a raised TIMP-1 level in PXF aqueous humour. The total MMP-9 in PXF aqueous humour remained low or undetectable, without significant corresponding changes. This supports the hypothesis of dysregulation in the matrix metabolism in PXF where the excessive TIMP-1 prevents the destruction of newly synthesised matrix, leading to PXF material accumulation. The presence of elevated $\mathrm{TGF} \beta_{1}{ }^{78}$ as well as reduced oxygen tensions ${ }^{635}$ in PXF aqueous humour may also contribute to the raised TIMP-1 levels, as TIMP-1 promoter contains a hypoxia response element. ${ }^{29}$ Our findings are consistent with a recent paper from Schlotzer-Schrehardt et al showing a significantly higher concentration of TIMP-1 in the aqueous humour of PXF eyes with or without glaucoma, and very low level of MMP-9 (15-55 pg/ml) requiring an ultrasensitive ELISA for quantification in all groups with no significant differences. ${ }^{36}$ In their study, TIMP-1 levels in the PXF eyes with $(\mathrm{n}=30)$ and without $(\mathrm{n}=30)$ glaucoma are 2 -fold and 1.8 -fold higher than their controls $(n=30)$, respectively. Similar results are indicated in our current study where our PXF eyes with $(\mathrm{n}=19)$ and without $(\mathrm{n}=37)$ glaucoma are 2 -fold and 1.5fold higher than the controls $(n=112)$. On the contrary, a smaller study conducted by Gartaganis et al found TIMP-1 levels in 19 normotensive PXF aqueous humour were slightly decreased, though not significantly so, compared to 15 normal controls. ${ }^{37}$ Nevertheless, comparisons between clinical studies are often difficult, owing to analytical and methodological (different types of ELISA kits used) variations.

CTGF is a member of an emerging family of regulatory proteins grouped together under the acronym CCN (CTGF, Cysteine-rich protein (CyR61), and Nephroblastoma overexpression gene (Nov)). Its overexpression is well described in various fibrotic disorders including scleroderma, renal and pulmonary fibrosis, inflammatory bowel disease, and atherosclerosis. ${ }^{16}{ }^{38}$ CTGF has the ability to affect the ECM metabolism by directly promoting collagen synthesis and regulating the expression of MMPs and TIMPs. ${ }^{39}$ Its potential role as a therapeutic target in controlling various ocular fibrotic diseases has been highlighted in recent studies related to corneal scarring, ${ }^{40}$ ocular cicatricial pemphigoid, ${ }^{41}$ and glaucoma filtration surgery. ${ }^{42}$ CTGF gene expression had also been demonstrated in human trabecular meshwork cells, ciliary body, retinal vascular endothelial cells, proliferative vitreoretinopathy membranes, choroidal neovascular membranes, cataractous plaque, corneal scars, tear fluid, and pterygia. $^{43-52}$

Our current study showed a significantly higher CTGF concentration in the aqueous humour of PXF glaucoma patients, which is suggestive of the involvement of CTGF in the fibrotic pathology of PXF syndrome and its association with glaucoma. The presence of CTGF had been found in human aqueous humour by western blot analysis ${ }^{43}{ }^{44}$ and ELISA. ${ }^{18}$ In their study, Van Setten et al reported the mean concentration of CTGF in 10 normal subjects without PXF as 1.24 (SD 0.26) $\mathrm{ng} / \mathrm{ml}^{18}$ compared with our current study where mean level in 29 controls eyes was 2.35 (SE 0.46) ng/ $\mathrm{ml}$. The difference may be attributed to the different ELISA used. Furthermore, the CTGF levels reported in our study are the values of the whole CTGF plus $\mathrm{N}$-terminal CTGF fragments.

There are several mechanisms that might account for the presence of certain growth factors in the aqueous humour. These include selective ultrafiltration of low molecular weight growth factors from serum, local intraocular synthesis and release of growth factors, diffusional exchange of growth factors between aqueous and vitreous humour, and selective transport systems for certain growth factors. ${ }^{2}$ The bloodaqueous barrier contributes partial control on the types and levels of growth factors that enter the aqueous humour in health and diseases. The drawbacks of our current aqueous humour study are that the raised elements found could be associated with the origin of disease development or, on the contrary, a consequential manifestation of the underlying pathology or maybe both. One could argue that it is the outflow obstruction that leads to the accumulation of TIMP-1 and CTGF. Similarly, the high levels of TIMP-1 and CTGF in the aqueous humour can be caused by excessive synthesis and give rise to the pathology.

The prevalence of PXF syndrome increases with age and its incidence doubles every decade after age $50 .{ }^{53}$ There is additional evidence recently demonstrating that PXF syndrome is a systemic condition where individuals with this condition appeared to have an increased incidence of hypertension, angina, myocardial infarction, stroke, aortic abdominal aneurysms, hyperhomocystinaemia, sensorineural hearing loss and dementia. ${ }^{54-59}$ Prevalence data for PXF in glaucoma populations vary considerably worldwide. ${ }^{6}$ A previous report from our department shows that $63 \%$ of the patients in our glaucoma clinics have PXF syndrome. ${ }^{60}$ Further work into understanding the mechanism of the development of PXF syndrome could allow us to have new therapeutic insights for treating PXF glaucoma. Regulation of MMP/TIMP expression and anti-CTGF therapy may offer potential therapeutic avenues for controlling PXF related ocular morbidity.

\section{Authors' affiliations}

S L Ho, C O'Brien, Department of Ophthalmology, Mater Misericordiae Hospital, Conway Institute, Dublin, Ireland

G F Dogar, A Murray, P E Cleary, Department of Ophthalmology, Cork University Hospital, Cork, Ireland

J Wang, Q D Wu, Surgical Research Laboratory, Cork University Hospital, Cork, Ireland 
J Crean, Department of Medicine and Therapeutics, Conway Institute, University College Dublin, Ireland

N Oliver, S Weitz, FibroGen, Inc, South San Francisco, CA, USA

Supported in part by research grants from Mater College for Postgraduate Education and International Glaucoma Association.

\section{REFERENCES}

1 Welge-Lüßen U, Albrecht May C, Neubauer AS, et al. Role of tissue growth factors in aqueous humor homeostasis. Curr Opin Ophthalmol $2001 ; 12: 94-9$

2 Tripathi RC, Borisuth NSC, Li J, et al. Growth factors in the aqueous humor and their clinical significance. J Glaucoma 1994;3:248-58.

3 Lutien-Drecoll E, Gabelt BAR, Tian B, et al. Oufflow of aqueous humor. J Glaucoma 2001;10(Suppl 1):S42-4.

4 Tomarev SI. Eyeing a new route along an old pathway. Nat Med 2001;7:294-5.

5 Ritch R. Perspective on exfoliation syndrome. J Glaucoma 2001;10(Suppl 1):S33-5.

6 Ritch R, Schlotzer-Schrehardt U. Exfoliation syndrome. Surv Ophthalmol 2001;45:265-315.

7 Schlotzer-Schrehardt U, Zenkel M, Kuchle M, et al. Role of transforming growth factor- $\beta 1$ and its latent form binding protein in pseudoexfoliation syndrome. Exp Eye Res 2001;73:765-80.

8 Koliakos GG, Schlotzer-Schrehardt U, Konstas AG, et al. Transforming and insulin-like growth factors in the aqueous humour of patients with exfoliation syndrome. Graefes Arch Clin Exp Ophthalmol 2001;239:482-7.

9 Gartaganis SP, Georgakopoulos CD, Exarchow AM, et al. Increased aqueous humour basic fibroblast growth factor and hyaluronan levels in relation to the exfoliation syndrome and exfoliative glaucoma. Acta Ophthalmol Scand $2001 ; 79: 572-5$

10 Hu DN, Ritch R. Hepatocyte growth factor is increased in the aqueous humor of glaucomatous eyes. J Glaucoma 2001;10:152-7.

11 Koliakos GG, Konstas AGP, Schlotzer-Schredardt U, et al. 8-Isoprostaglandin $\mathrm{F}_{2 \mathrm{a}}$ and ascorbic acid concentration in the aqueous humour of patients with exfoliation syndrome. Br J Ophthalmol 2003;87:353-6.

12 Baricos WH, Cortez SL, Deboisblanc M, et al. Transforming growth factorbeta is a potent inhibitor of extracelluar matrix degradation by cultured human mesangial cells. J Am Soc Nephrol 1999;10:790-5.

13 Ziyadeh FN, Han DC. Involvement of transforming growth factor beta and its receptors in the pathogenesis of diabetic nephrology. Kidney Int 1997:60:S7-11.

14 Laiho M, Saksela O, Keski-Oja J. Transforming growth factor beta alters plasminogen activator activity in human skin fibroblasts. Exp Cell Res $1986 ; 164: 399-407$.

15 Huang SH, Adamis AP, Wiederschanin DG et al. Matrix metalloproteinases and their inhibitors in aqueous humor. Exp Eye Res 1996;62:481-90.

16 Crean JKG, Lappin DWP, Godson C, et al. Connective tissue growth factor: an attractive therapeutic target in fibrotic renal disease. Expert Opin Ther Targets 2001;5:519-30.

17 Moussad EE, Brigstock DR. Connective tissue growth factor: what's in a name. Mol Genet Metab 2000;71:276-92.

18 Van Setten GB, Blalock TD, Grotendorst G, et al. Detection of connective tissue growth factor in human aqueous humor. Ophthalmic Res 2002;34:306-8.

19 Usinger W, Krueger M, Gray J, et al. CTGF N fragment-a nw marker for fibrosis. ASN (American Society of Nephrology) abstract 2002 \#P, 0143.

20 Brigstock DR, Steffen CL, Kim GY, et al. Purification and characterization of novel heparin-binding growth factors in uterine secretory fluids. Identification as heparin-regulated $\mathrm{Mr} 10,000$ forms of connective tissue growth factor. $J$ Biol Chem 1997;272:20275-82.

21 Ball DK, Surveyor GA, Diehl JR, et al. Characterization of 16- to 20 kilodalton ( $\mathrm{kDa}$ ) connective tissue growth factors (CTGFs) and demonstration of proteolytic activity for 38-kDa CTGF in pig uterine luminal flushings. Biol Reprod 1998:59:828-35.

22 Steffan CL, Ball-Mirth DK, Harding PA, et al. Characterization of cellassociation and soluble forms of connective tissue growth factor (CTGF) produced by fibroblast cells in vitro. Growth Factors 1998;15:199-213.

23 Gottanka J, Flugel-Koch C, Martus P, et al. Correlation of pseudoexfoliation material and optic nerve damage in pseudoexfoliation syndrome. Invest Ophthalmol Vis Sci 1997;38:2435-46.

24 El-Shabrawi Y, Eckhardt M, Berghold A, et al. Synthesis pattern of matrix metalloproteinases (MMPs) and inhibitors (TIMPs) in human explant organ cultures after treatment with latanoprost and dexamethasone. Eye 2000; 14(P+3A):375-83

25 Mietz H, Esser JM, Welsandt G, et al. Latanoprost stimulates secretion of matrix metalloproteinases in tenon fibroblasts both in vitro and in vivo. Invest Ophthalmol Vis Sci 2003;44:5182-8.

26 Anthony TL, Lindsey JD, Weinreb R. Latanoprost's effects on TIMP-1 and TIMP-2 expression in human ciliary muscle cells. Invest Ophthalmol Vis Sci 2002;43:3705-11.

27 Meitz H, Schlotzer-Schrehardt U, Strassfeld C, et al. Effect of latanoprost and timolol on the histopathology of the rabbit conjunctiva. Invest Ophthalmol Vis Sci 2001;42:679-87.

28 Salzman J, Limb GA, Khaw PT, et al. Matrix metalloproteinases and their natural inhibitors in fibrovascular membranes of proliferative diabetic retinopathy. Br J Ophthalomol 2000;84:1091-6.

29 Sethi CS, Bailey TA, Luthert PJ, et al. Matrix metalloproteinase biology applied to vitreoretinal disorders. Br J Ophthalmol 2000;84:654-66.
30 Pang $\mathrm{IH}$, Hellberg PE, Fleenor DL, et al. Expression of matrix metalloproteinases and their inhibitors in human trabecular meshwork cells. Invest Ophthalmol Vis Sci 2003;44:3485-93.

31 Bradley JM, Vranka J, Colvis CM, et al. Effect of matrix metalloproteinases activity on oufflow in perfused human organ culture. Invest Ophthalmol Vis Sci 1998;39:2649-58

32 Alexander JP, Samples JR, Acott TS. Growth factor and cytokine modulation of trabecular meshwork matrix metalloproteinase and TIMP expression. Curr Eye Res 1998;17:276-85

33 Samples JR, Alexander JP, Acott TS. Regulation of the levels of human trabecular matrix metalloproteinases and inhibitor by interleukin-1 and dexamethasone. Invest Ophthalmol Vis Sci 1993;34:3386-95.

34 O'Connell JP, Willenbrock F, Docherty AJ, et al. Analysis of the role of the $\mathrm{COOH}$-terminal domain in the activation, proteolytic activity, and tissue inhibitor of metalloproteinase interactions of gelatinase B. J Biol Chem 1994;269:14967-73

35 Naumann GOH, Schlotzer-Schrehardt U, Kuchle M. Pseudoexfoliation syndrome for the comprehensive ophthalmologist. Ophthalmology 1998; 105:951-68.

36 Schlotzer-Schrehardt U, Lommatzsch J, Kuchle M, et al. Matrix metalloproteinases and their inhibitors in aqueous humour of patients with pseudoexfoliation syndrome/glaucoma and primary open-angle glaucoma. Invest Ophthalmol Vis Sci 2003:44:1117-25.

37 Gartaganis SP, Georgakopoulos CD, Mela EK, et al. Matrix metalloproteinases and their inhibitors in exfoliation syndrome. Ophthalmic Res 2002;34:165-71

38 Oemar BS, Luscher TF. Connective tissue growth factor: friend or foe? Arterioscler Thromb Vasc Biol 1997;17:1483-9.

39 Brigstock DR. Regulation of angiogenesis and endothelial cell function by connective tissue growth factor (CTGF) and cysteine-rich 61 (CYR61). Angiogenesis 2002;5:153-65

40 Blalock TD, Duncan MR, Varela JC, et al. Connective tissue growth factor expression and action in human corneal fibroblast cultures and rat corneas after photorefractive keratectomy. Invest Ophthalmol Vis Sci 2003:44:1879-87.

41 Razzaque MS, Foster CS, Ahmed AR. Role of connective tissue growth factor in the pathogenesis of conjunctival scarring in ocular cicatricial pemphigoid. Invest Ophthalmol Vis Sci 2003;44:1998-2003.

42 Esson DW, Neelakantan A, lyer SA, et al. Expression of connective tissue growth factor after glaucoma filtration surgery in a rabbit model. Invest Ophthalmol Vis Sci 2004;45:485-91.

43 Deng P, Maddala RL, Khurana RN, et al. Expression and regulation of connective tissue growth factor in human trabecular meshwork cells and tissue. (ARVO 2002, Abstract no 1032).

44 Shepard AR, Fleenor D, Jacobson N, et al. Connective tissue growth factor expression in glaucomatous human TM cells and aqueous humor and upregulation by TGF $\beta 2$. (ARVO 2003, Abstract no 3161).

45 Wunderlich K, Senn BC, Todesco L, et al. Regulation of connective tissue growth factor gene expression in retinal vascular endothelial cells by angiogenic growth factors. Graefes Arch Clin Exp Ophthalmol 2000;238:910-15.

46 Hinton DR, He S, Jin ML, et al. Novel growth factors in the pathogenesis of proliferative vitreoretinopathy. Eye 2002;16:422-8.

$47 \mathrm{He} \mathrm{S}$, Jin ML, Worpel V, et al. A role for connective tissue growth factor in the pathogenesis of choroidal neovascularization. Arch Ophthalmol 2003:121:1283-8.

48 Wunderlich $\mathrm{K}$, Pech $\mathrm{M}$, Eberle AN, et al. Expression of connective tissue growth factor (CTGF) mRNA in plaques of human anterior subcapsular cataracts and membranes of posterior capsule opacification. Curr Eye Res 2000;21:627-36

49 Lee EH, Joo CK. Role of transforming growth factor-beta in transdifferentiation and fibrosis of lens epithelial cells. Invest Ophthalmol Vis Sci 1999;40:2025-32.

50 Wunderlich K, Senn BC, Reiser P, et al. Connective tissues growth factor in retrocorneal membranes and corneal scars. Ophthalmologica 2000;214:341-6.

51 Van Setten GB, Blalock TD, Grotendorst G, et al. Detection of connective tissue growth factor (CTGF) in human tear fluid: preliminary results. Acto Ophthalmol Scand 2003;81:51-3.

52 Van Setten G, Aspiotis M, Blalock TD, et al. Connective tissue growth factor in pterygium: simultaneous presence with vascular endothelial growth factorpossible contributing factor to conjunctival scarring. Graefes Arch Clin Exp Ophthalmol 2003;241:135-9.

53 Forsius H. Exfoliation syndrome in various ethnic populations. Acto Ophthalmol Suppl 1988;184:71-85.

54 Mitchell P, Wang JJ, Smith W. Association of pseudoexfoliation syndrome with increased vascular risk. Am J Ophthalmol 1997; 124:685-7.

55 Schumacher S, Schlotzer-Schrehardt U, Martus P, et al. Pseudoexfoliation syndrome and aneurysms of the abdominal aorta. Lancet 2001;357:359-60.

56 Leibovitch I, Kurtz S, Shemesh G, et al. Hyperhomocystinemia in pseudoexfoliation glaucoma. J Glaucoma 2003;12:36-9.

57 Vessani RM, Ritch R, Liebmann JM, et al. Plasma homocysteine is elevated in patients with exfoliation syndrome. Am J Ophthalmol 2003;136:41-6.

58 Cahill M, Early A, Stack S, et al. Pseudoexfoliation and sensorineural hearing loss. Eye 2002;16:261-6

59 Linner E, Popovic V, Gottfries CG, et al. The exfoliation syndrome in cognitive impairment of cerebrovascular or Alzheimer's type. Acta Ophthalmol Scand $2001 ; 79: 283-5$.

60 Madden JG, Crowley MJ. Factors in the exfoliation syndrome. Br J Ophthalmol 1982;66:432-7. 